\title{
RADIOCARBON DATING OF ALKENONES FROM MARINE SEDIMENTS: III. INFLUENCE OF SOLVENT EXTRACTION PROCEDURES ON ${ }^{14} \mathrm{C}$ MEASUREMENTS OF FORAMINIFERA
}

\author{
Naohiko Ohkouchi ${ }^{1,2} \bullet$ Timothy I Eglinton ${ }^{1,3} \bullet \operatorname{Konrad}$ H Hughen $^{1} \bullet$ Ellen Roosen $^{4} \bullet$ \\ Lloyd D Keigwin ${ }^{4}$
}

ABSTRACT. As a result of the growing use of multiple geochemical proxies to reconstruct ocean and climate changes in the past, there is an increasing need to establish temporal relationships between proxies derived from the same marine sediment record and ideally from the same core sections. Coupled proxy records of surface ocean properties, such as those based on lipid biomarkers (e.g. alkenone-derived sea surface temperature) and planktonic foraminiferal carbonate (oxygen isotopes), are a key example. Here, we assess whether 2 different solvent extraction procedures used for isolation of molecular biomarkers influence the radiocarbon contents of planktonic foraminiferal carbonate recovered from the corresponding residues of Bermuda Rise and Cariaco Basin sediments. Although minor $\Delta^{14} \mathrm{C}$ differences were observed between solvent-extracted and unextracted samples, no substantial or systematic offsets were evident. Overall, these data suggest that, in a practical sense, foraminiferal shells from a solvent-extracted residue can be reliably used for ${ }^{14} \mathrm{C}$ dating to determine the age of sediment deposition and to examine age relationships with other sedimentary constituents (e.g. alkenones).

\section{INTRODUCTION}

Determination of accurate chronologies for sedimentary sequences is a key prerequisite for interpretation of these records in relation to climate history. The measurement of radiocarbon abundance in planktonic foraminiferal shells has proven to be a particularly effective means of developing age models for marine sediments deposited over the late Quaternary (e.g. Bowman 1990; Bradley 1999). This approach is also appealing because the relative abundance, stable carbon and oxygen isotopic, and elemental compositions of these same microfossils yield important proxy records of surface ocean properties.

More recently, molecular proxies utilizing the abundance and isotopic compositions of organic compounds have become an integral component of paleoceanographic studies (e.g. Brassell 1993; Harris et al. 1996; Pagani et al. 2002; Ohkouchi et al. 1997; Sinninghe Damsté and Köster 1998; Hughen et al. 2004), and the use of multiple proxies to reinforce paleoclimate interpretations and to derive new parameters is now commonplace (e.g. Meyers 1997; Rostek et al. 1993).

Ideally, multiproxy sediment records should be developed based on parallel measurements of the same sediment samples. This is particularly important in instances where microfossil and molecular data are used in concert to derive new information (e.g. Rostek et al. 1993; Hughen et al. 2004). Measurements on the same samples are also desirable to conserve sediment where available sample quantities are limited. Lastly, it is becoming increasingly apparent that it is important to establish age relationships between proxies in the same sediment record (Ohkouchi et al. 2002; Mollenhauer et al. 2003; Mollenhauer et al. 2005). Historically, however, measurements based on forams are typically undertaken independently of those for molecular proxy measurements due to different storage, processing, and analytical practices.

This study was designed to examine the effects of conventional organic geochemical procedures (solvent extraction) used to isolate molecular biomarkers on the carbon isotopic composition $\left({ }^{14} \mathrm{C}\right.$,

\footnotetext{
${ }^{1}$ Department of Marine Chemistry and Geochemistry, Woods Hole Oceanographic Institution, Woods Hole, Massachusetts 02543, USA.

${ }^{2}$ Present address: Institute for Research on Earth Evolution, 2-15 Natsushimacho, Yokosuka 237-0061, Japan.

${ }^{3}$ Corresponding author. Email: teglinton@whoi.edu.

${ }^{4}$ Department of Geology and Geophysics, Woods Hole Oceanographic Institution, Woods Hole, Massachusetts 02543, USA.
} 
${ }^{13} \mathrm{C}$ ) of foraminiferal carbonate residing in the resulting sediment residue. We applied 2 different types of common solvent extraction techniques: one is Soxhlet extraction, a conventional method to extract lipids from the sediments, and the other is accelerated solvent extraction (ASE), a more rapid technique that has recently been established (Richter 1999) and has gained popularity in molecular proxy-based paleoclimate investigations (Herbert et al. 1998; Sachs and Lehman 1999). The main goal was to establish whether or not solvent-extracted residues are suitable materials for the subsequent isolation of foraminifera for the purposes of developing sediment ${ }^{14} \mathrm{C}$ chronologies. The study forms part of an investigation to examine ${ }^{14} \mathrm{C}$ contents of co-occurring planktonic foraminifera and biomarkers (alkenones) in marine sediments. Companion papers (Ohkouchi et al., this issue; Mollenhauer et al., this issue) describe a method for isolation of one class of molecular biomarkers, the alkenones, and assess the sources and magnitude of carbon blanks associated with alkenone ${ }^{14} \mathrm{C}$ analysis.

\section{EXPERIMENTAL}

The samples used in this study are sediments from the upper portion $(0-2 \mathrm{~cm})$ of a box core (OCE326-BC9) recovered from the northeastern flank of Bermuda Rise $\left(33^{\circ} 41.6^{\prime} \mathrm{N}, 57^{\circ} 36.7^{\prime} \mathrm{W}\right.$, $4517 \mathrm{~m}$ water depth) and the 389.5-391-cm depth interval of a piston core (PL07-58PC) from the central Cariaco Basin $\left(10^{\circ} 40.1^{\prime} \mathrm{N}, 64^{\circ} 58.1^{\prime} \mathrm{W}, 820 \mathrm{~m}\right.$ water depth; Hughen et al. 1996). The Bermuda Rise sediments were deposited under oxic bottom waters and exhibited carbonate and organic carbon contents of 18.7 and $0.61 \%$, respectively (N Ohkouchi and T I Eglinton, unpublished results; Keigwin and Boyle 2000). The planktonic foraminifera Globigerinoides ruber and Globolotaria inflata are abundant in Holocene sediments from this location. In contrast, Cariaco Basin sediments were deposited under anoxic conditions and maintain high OC and carbonate contents (2-5\% and $20-25 \%$, respectively) from the late glacial through to the present. The planktic foraminifera Globigerina bulloides and G. ruber are abundant, particularly following deglaciation $(0-15,000 \mathrm{cal} \mathrm{BP})$, and show excellent preservation (Hughen et al. 1996). Sediments were obtained from approximately $10,500 \mathrm{cal} \mathrm{BP}$, and each sample comprised 10-15 yr of deposition.

The sediments were homogenized by a spatula and air-dried $\left(50{ }^{\circ} \mathrm{C}\right)$ before being separated into 3 aliquots. The first aliquot $(\sim 20 \mathrm{~g})$ was placed in a precleaned cellulose thimble and extracted using a Soxhlet apparatus with a solvent mixture of methanol $(\mathrm{MeOH})$ and dichloromethane $\left(\mathrm{CH}_{2} \mathrm{Cl}_{2} ; 1: 3\right.$, v/v) for 4 days. In this procedure, the solvent mixture is refluxed; the solvents condense and then percolate through the sample. The solvent and any organic material dissolved in the solvent then siphons back into the refluxing vessel, where the cycle is repeated. This procedure is therefore considered mild from a physical standpoint, as well as in terms of the temperatures that the sediment sample experiences $\left(<50^{\circ} \mathrm{C}\right)$.

The second aliquot was processed by accelerator solvent extraction (Dionex ASE ${ }^{\circledR} 200$ ). The sediment $(\sim 10 \mathrm{~g})$ was packed between 2 glass fiber filters $(0.7 \mu \mathrm{m}$ pore size $)$ and clean sand in stainless steel pressure vessels. Rapid extraction of lipids is achieved by passing $\mathrm{MeOH}$ and $\mathrm{CH}_{2} \mathrm{Cl}_{2}$ $(1: 9, \mathrm{v} / \mathrm{v})$ over the sample at elevated temperatures and pressures $\left(1000 \mathrm{psi}, 100{ }^{\circ} \mathrm{C}\right.$ for $\left.25 \mathrm{~min}\right)$. As a control, the third aliquot of the sediment was left unprocessed.

The unprocessed (unextracted) sediment and the dried residues from Soxhlet and ASE extractions were initially sieved to recover a coarse fraction $(>63 \mu \mathrm{m})$, and planktonic foraminifera were subsequently picked from the 100-250- $\mu \mathrm{m}$ or $>250-\mu \mathrm{m}$ fractions. G. ruber and G. inflata were picked from the Bermuda Rise samples and G. ruber and G. bulloides were picked from the Cariaco Basin samples. The isolated foraminifera were gently agitated in $\mathrm{MeOH}$ and distilled water to displace any fine-grained material from the shells. The cleaned foraminifera were then examined under the 
microscope to confirm the cleanliness and integrity of the shells before being submitted to the National Ocean Sciences Accelerator Mass Spectrometry (NOSAMS) facility for subsequent ${ }^{14} \mathrm{C}$ analysis. Samples were prepared for AMS using conventional procedures (McNichol et al. 1994).

All sample sizes were larger than $1 \mathrm{mg} \mathrm{C}$ and yielded ${ }^{14} \mathrm{C}$ results at full precision $(<5 \%)$. Machine, source, and graphitization blanks at NOSAMS are also negligibly small in the context of discussing potential influences of solvent treatments on foraminiferal ${ }^{14} \mathrm{C}$ (Pearson et al. 1998).

The $\delta^{13} \mathrm{C}$ values of Bermuda Rise samples were measured at NOSAMS using a small aliquot of $\mathrm{CO}_{2}$ gas produced by the acid hydrolysis (McNichol et al. 1994). In contrast, the $\delta^{13} \mathrm{C}$ values of Cariaco Basin samples were determined independently from the $\Delta^{14} \mathrm{C}$ measurements at one of the author's (LDK's) laboratory. The analytical precision for each method is less than or equal to $\pm 0.10 \%$ o.

\section{RESULTS AND DISCUSSION}

\section{Bermuda Rise Sediment}

Table 1 summarizes ${ }^{14} \mathrm{C}$ and ${ }^{13} \mathrm{C}$ results from the samples investigated in this study. Figure 1 shows $\Delta{ }^{14} \mathrm{C}$ values of G. ruber and G. inflata collected from the Bermuda Rise sediments as a function of $\delta^{13} \mathrm{C}$. The $\Delta^{14} \mathrm{C}_{\text {ruber }}$ ranged from -136 to $-149 \%$, whereas $\Delta{ }^{14} \mathrm{C}_{\text {inflata }}$ varied from -150 to $-163 \%$, with the ASE-extracted samples being the highest (youngest) for both species (Table 1). The agreement between duplicate $\Delta{ }^{14} \mathrm{C}$ measurements of $G$. inflata is in each case within the precision of the method.

Table 1 Summary of $\delta^{13} \mathrm{C}$ and AMS ${ }^{14} \mathrm{C}$ analytical results of planktonic foraminifera from Bermuda Rise and Cariaco Basin sediments.

\begin{tabular}{|c|c|c|c|c|c|c|}
\hline Site & Core & Extraction & Foraminifera & $\begin{array}{l}\delta^{13} \mathrm{C} \\
(\% \circ ; \mathrm{PDB})\end{array}$ & $\begin{array}{l}\Delta^{14} \mathrm{C} \\
(\% \circ \pm 1 \sigma)\end{array}$ & $\begin{array}{l}{ }^{14} \mathrm{C} \text { age } \\
\text { (BP) }\end{array}$ \\
\hline \multirow{9}{*}{ Bermuda Rise } & \multirow{9}{*}{ BC9 } & \multirow{3}{*}{$\mathrm{ASE}^{\mathrm{a}}$} & G. ruber & 0.32 & $-131.2 \pm 4.3$ & $1130 \pm 40$ \\
\hline & & & G. inflata & 0.61 & $-145.2 \pm 4.2$ & $1260 \pm 35$ \\
\hline & & & G. inflata & 0.71 & $-147.3 \pm 4.8$ & $1280 \pm 45$ \\
\hline & & \multirow{3}{*}{ Soxhlet } & G. ruber & 0.60 & $-144.1 \pm 3.7$ & $1250 \pm 35$ \\
\hline & & & G. inflata & n.d.b & $-148.4 \pm 4.2$ & $1290 \pm 40$ \\
\hline & & & G. inflata & 0.71 & $-148.4 \pm 4.8$ & $1290 \pm 45$ \\
\hline & & \multirow[t]{3}{*}{ Unextracted } & G. ruber & 0.61 & $-136.6 \pm 3.8$ & $1180 \pm 35$ \\
\hline & & & G. inflata & 0.64 & $-153.6 \pm 3.7$ & $1340 \pm 35$ \\
\hline & & & G. inflata & 0.67 & $-157.8 \pm 4.2$ & $1380 \pm 40$ \\
\hline \multirow[t]{9}{*}{ Cariaco Basin } & \multirow[t]{9}{*}{$58 \mathrm{PC}$} & \multirow[t]{3}{*}{ ASE } & G. ruber & $0.00^{c}$ & $-698.8 \pm 1.9$ & $9640 \pm 50$ \\
\hline & & & G. bulloides & $-2.12^{\mathrm{c}}$ & $-701.4 \pm 2.0$ & $9710 \pm 55$ \\
\hline & & & G. bulloides & n.d. & $-698.4 \pm 2.2$ & $9630 \pm 60$ \\
\hline & & \multirow[t]{3}{*}{ Soxhlet } & G. ruber & $0.36^{c}$ & $-705.9 \pm 2.0$ & $9830 \pm 55$ \\
\hline & & & G. bulloides & $-1.86^{c}$ & $-709.1 \pm 2.2$ & $9920 \pm 60$ \\
\hline & & & G. bulloides & n.d. & $-705.9 \pm 2.0$ & $9830 \pm 55$ \\
\hline & & \multirow[t]{3}{*}{ Unextracted } & G. ruber & $-0.03^{c}$ & $-704.0 \pm 4.0$ & $9780 \pm 110$ \\
\hline & & & G. bulloides & $-2.05^{\mathrm{c}}$ & $-697.7 \pm 2.2$ & $9610 \pm 60$ \\
\hline & & & G. bulloides & n.d. & $-702.9 \pm 2.6$ & $9750 \pm 70$ \\
\hline
\end{tabular}

accelerator solvent extractor.

b Not determined.

${ }^{\mathrm{c}} \delta^{13} \mathrm{C}$ values were determined independently from $\Delta^{14} \mathrm{C}$ measurements. 


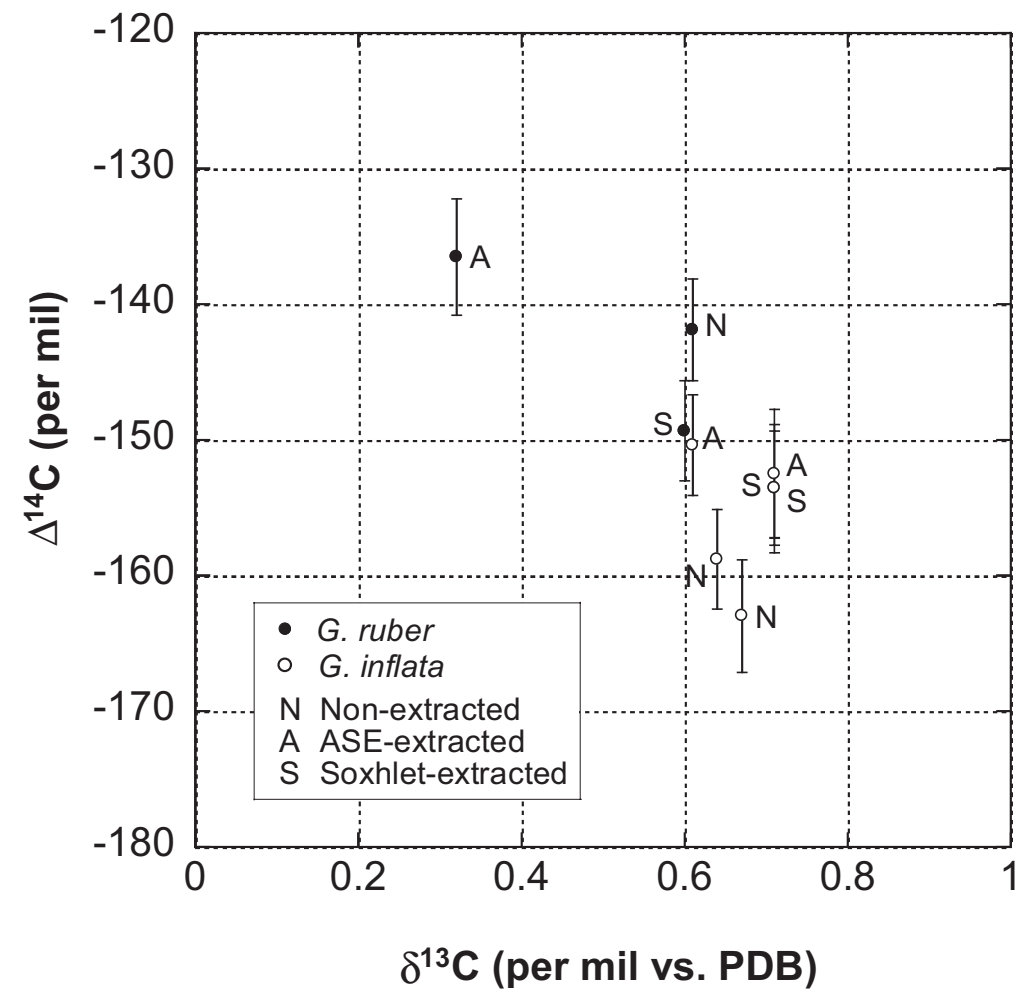

Figure 1 A $\Delta{ }^{14} \mathrm{C}-\delta^{13} \mathrm{C}$ plot of planktonic foraminifera G. ruber and G. inflata from Bermuda Rise sediment OCE326-BC9C. Note that one of the $\delta^{13} \mathrm{C}$ values of $G$. inflata from the Soxhlet-extracted sediments was assumed to have the same $\delta^{13} \mathrm{C}$ value as the other duplicate. All $\Delta^{14} \mathrm{C}$ errors are $1 \sigma$.

Greater variability is observed in the ${ }^{13} \mathrm{C}$ data. While the $\delta^{13} \mathrm{C}$ values of $G$. inflata generally vary within a narrow range (between 0.60 and $0.71 \%$ ), the ASE-extracted G. ruber yield a $\delta^{13} \mathrm{C}$ value $(0.32 \%$ ) that is depleted relative to the corresponding Soxhlet-extracted $(0.60 \%)$ and unextracted samples $\left(0.61 \%\right.$ ). Deuser and Ross (1989) reported that $\delta^{13} \mathrm{C}_{\text {ruber }}$ in modern sinking particles range from 0.4 to $1.2 \%$ o seasonally based on analyses of time-series sediment-trap samples from the Sargasso Sea $\left(32^{\circ} 05^{\prime} \mathrm{N}, 64^{\circ} 15^{\prime} \mathrm{W}\right)$. Given that surface water hydrology about ${ }^{1200-1400}{ }^{14} \mathrm{C}$ yr ago is unlikely to have been substantially different from the present day, and that $\delta^{13} \mathrm{C}$ values of individual planktic foraminifera in these sediments can vary substantially (L D Keigwin, unpublished results), we conclude that these $\delta^{13} \mathrm{C}$ variations are consistent with the ecology of G. ruber and G. inflata.

The $\Delta^{14} \mathrm{C}_{\text {ruber }}$ values for both Soxhlet-extracted and unextracted samples are isotopically enriched compared to $\Delta^{14} C_{\text {inflata }}$, by 4 and $17-21 \%$, respectively. The difference in $\Delta^{14} \mathrm{C}$ between these 2 species may be explained by differences in dissolved inorganic carbon (DIC) $\Delta^{14} \mathrm{C}$ resulting from the different seasons and depths at which these species precipitate their shells. G. inflata grows in the surface mixed layer $(\sim 75 \mathrm{~m})$ mainly from February to March when upwelling is strengthened, whereas $G$. ruber lives in the uppermost euphotic zone from summer to autumn when surface waters are stratified due to the presence of a seasonal thermocline in the lower euphotic zone (Deuser and Ross 1989). Therefore, when G. ruber precipitates the shell, the DIC in the surface water should be more strongly influenced by atmospheric $\mathrm{CO}_{2}$, which is relatively enriched in ${ }^{14} \mathrm{C}$. In contrast, dur- 
ing calcification of G. inflata, surface water DIC is more strongly influenced by the upwelling of deeper water. Based on the 1972-1973 GEOSECS data, Broecker and Peng (1980) estimated an annual amplitude of $\Delta^{14} \mathrm{C}$ of the DIC in the surface water near Bermuda Island (around $35^{\circ} \mathrm{N}, 50^{\circ} \mathrm{W}$ ) of about $35 \%$. The seasonal variation of surface water $\Delta^{14} \mathrm{C}_{\mathrm{DIC}}$ before anthropogenic perturbation is likely to have been significantly smaller because of the reduced difference of $\Delta^{14} \mathrm{C}$ between atmospheric $\mathrm{CO}_{2}$ and upwelled DIC compared to post-bomb values (Levin et al. 1985). In this sense, the $4 \%$ difference observed in the Soxhlet-extracted sediments may be more reasonable than that of the unextracted and ASE-extracted samples, which show larger differences. In each case, however, these variations are close to the precision of the measurement. As far as the Bermuda Rise sediment sample is concerned, we therefore conclude that the differences in foraminiferal $\Delta^{14} \mathrm{C}$ values in the unextracted, Soxhlet-extracted, and ASE-extracted samples are small and do not introduce any significant uncertainty into the age determinations.

\section{Cariaco Basin Sediment}

Some variability was observed in the ${ }^{13} \mathrm{C}$ data from Cariaco Basin sediments (Figure 2). Both the $\delta^{13} \mathrm{C}$ values of G. ruber and G. bulloides generally vary in the range of -0.03 and $0.36 \%$, and -2.12 and $-1.86 \%$, respectively. The Soxhlet-extracted samples of both species are somewhat enriched in ${ }^{13} \mathrm{C}(\sim 0.4 \%$ ) relative to the corresponding ASE-extracted and unextracted samples.

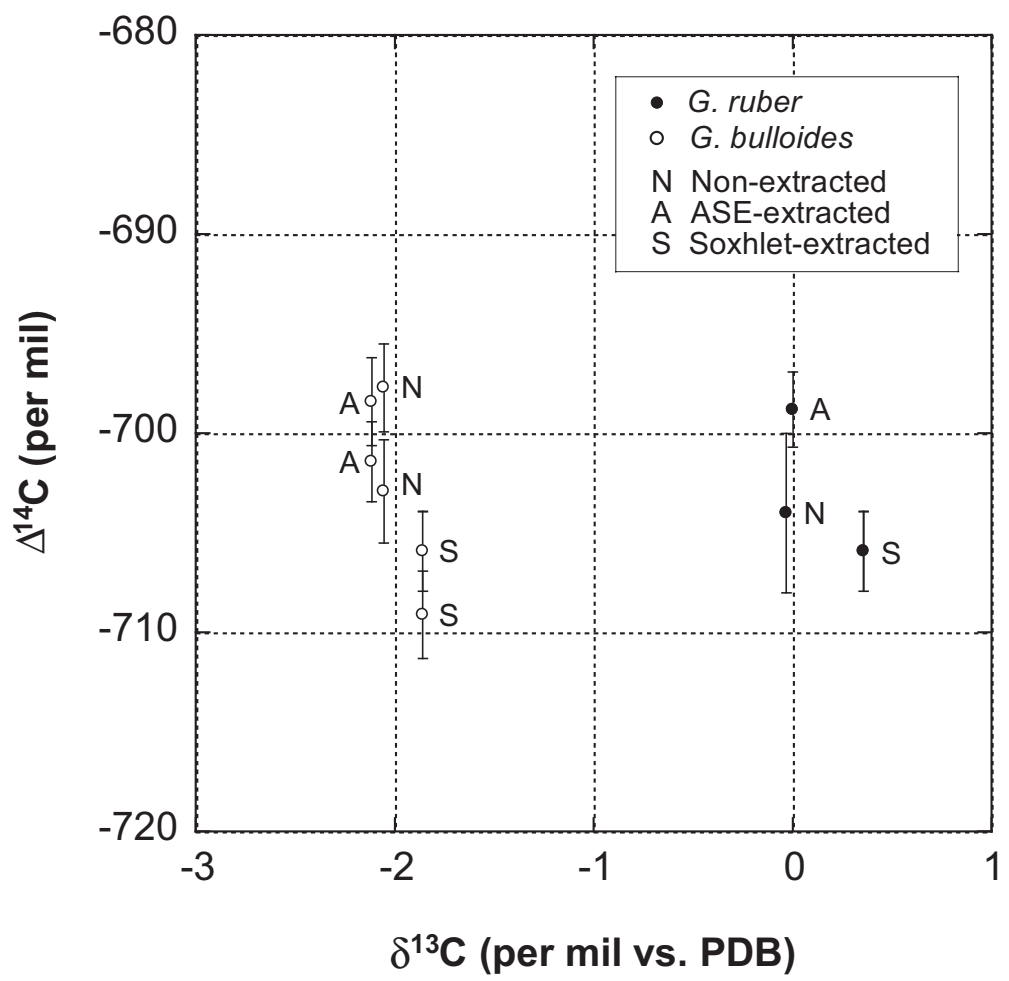

Figure 2 A $\Delta^{14} \mathrm{C}-\delta^{13} \mathrm{C}$ plot of planktonic foraminifera G. ruber and G. bulloides from Cariaco Basin sediments (PL07-58PC). Note that the $\delta^{13} \mathrm{C}$ of these foraminifera were independently determined using foraminifera shell different from those where $\Delta^{14} \mathrm{C}$ were measured. We assumed that the G. bulloides have the same $\delta^{13} \mathrm{C}$ values as the other duplicate. All $\Delta^{14} \mathrm{C}$ errors are $1 \sigma$. 
The $\Delta^{14} \mathrm{C}$ results from the Cariaco Basin exhibit a slightly different pattern from those of the Bermuda Rise (Figure 2, Table 1). The Soxhlet-extracted samples yielded $\Delta^{14} \mathrm{C}$ values that are somewhat $(<10 \%)$ lower than those of the corresponding ASE-extracted sediment for both G. ruber and G. bulloides. Although the differences are within error, it is interesting to note that the $\Delta^{14} \mathrm{C}_{\text {ruber }}$ is 1.1 and $1.6 \%$ higher than the average $\Delta^{14} \mathrm{C}_{\text {bulloides }}$ value in the ASE- and Soxhlet-extracted samples, respectively, whereas it is $3.7 \%$ o lower than $\Delta^{14} \mathrm{C}_{\text {bulloides }}$ in the unextracted samples. Theoretically, the $\Delta^{14} \mathrm{C}_{\text {ruber }}$ should be somewhat higher than $\Delta^{14} \mathrm{C}_{\text {bulloides }}$, consistent with the results of the extracted samples, because $G$. ruber is specific to the warmer temperatures of the non-upwelling rainy season (July-November), whereas G. bulloides is a colder-water species that grows in the upwelling season (January-April) (Lin et al. 1997). Unfortunately, no direct information is presently available on the seasonal $\Delta{ }^{14} \mathrm{C}_{\mathrm{DIC}}$ variation in the surface water of Cariaco Basin, and thus we cannot quantitatively verify the difference observed in this study.

Since blank levels of machine, source, and graphitization are minimal for large samples such as those examined here ( $>1 \mathrm{mg}$ C; Pearson et al. 1998), the $\Delta^{14} \mathrm{C}$ variations observed in the Bermuda and Cariaco samples could reflect varying degrees of contamination of the sample itself. Foraminiferal shells have various potential sources of contamination: fine-grained material that contains carbonate and organic matter trapped within the chambers, secondary carbonate encrusted on the shell, organic matter in the carbonate lattice, and adsorbed atmospheric $\mathrm{CO}_{2}$. Schleicher et al. (1998) systematically investigated the ${ }^{14} \mathrm{C}$-blank level of foraminiferal samples and concluded that the major ${ }^{14} \mathrm{C}$ contamination is derived from carbonate rather than from organic matter. Although this study did not address contamination by infinite ${ }^{14} \mathrm{C}$-age materials (fossil C) due to the use of ${ }^{14} \mathrm{C}$-free $\left({ }^{14} \mathrm{C}\right.$ $\mathrm{dead}$ ) foraminifera, some of these contamination sources, including carbonate, may exist in our samples because it is difficult to ensure complete removal of all exogenous carbon. The ASE- and Soxhlet-extracted samples may have additional carbon due to the presence of residual solvent (known to be ${ }^{14} \mathrm{C}$-dead) or a small amount of impurities in the solvent.

Figure 3 summarizes the differences in foraminiferal $\Delta^{14} \mathrm{C}$ between unextracted and extracted sediments. There appear to be no major differences between extracted and unextracted samples. Importantly, the differences are generally small $(<10 \%)$ and close to the precision of the AMS ${ }^{14} \mathrm{C}$ measurement. Although variations are minor, some systematic differences are apparent. One consistent feature is that the $\Delta^{14} \mathrm{C}$ values of foraminiferal carbonate from the ASE-extracted sediments are 2-8\%o higher than those from the corresponding Soxhlet-extracted sediments (Figure 3). Because the solvents are not expected to cause dissolution, we consider it unlikely that ASE treatment exposes fresh calcite surfaces that promote $\mathrm{CO}_{2}$ adsorption. A more likely explanation is that foram treatment for ${ }^{14} \mathrm{C}$ typically includes repeated sonication, but not crushing the chambers to expose the interior. It is possible that carbonate particles might possibly persist after sonication but are removed by high temperature and pressure solvents in the ASE.

Overall, the differences in foraminiferal ${ }^{14} \mathrm{C}$ between unextracted and solvent-extracted sediments from both the Bermuda Rise and the Cariaco Basin are small and approach the precision of the measurement. Based on these findings, we conclude that little accuracy is sacrificed in working with solvent-extracted as opposed to non-extracted sediments. 


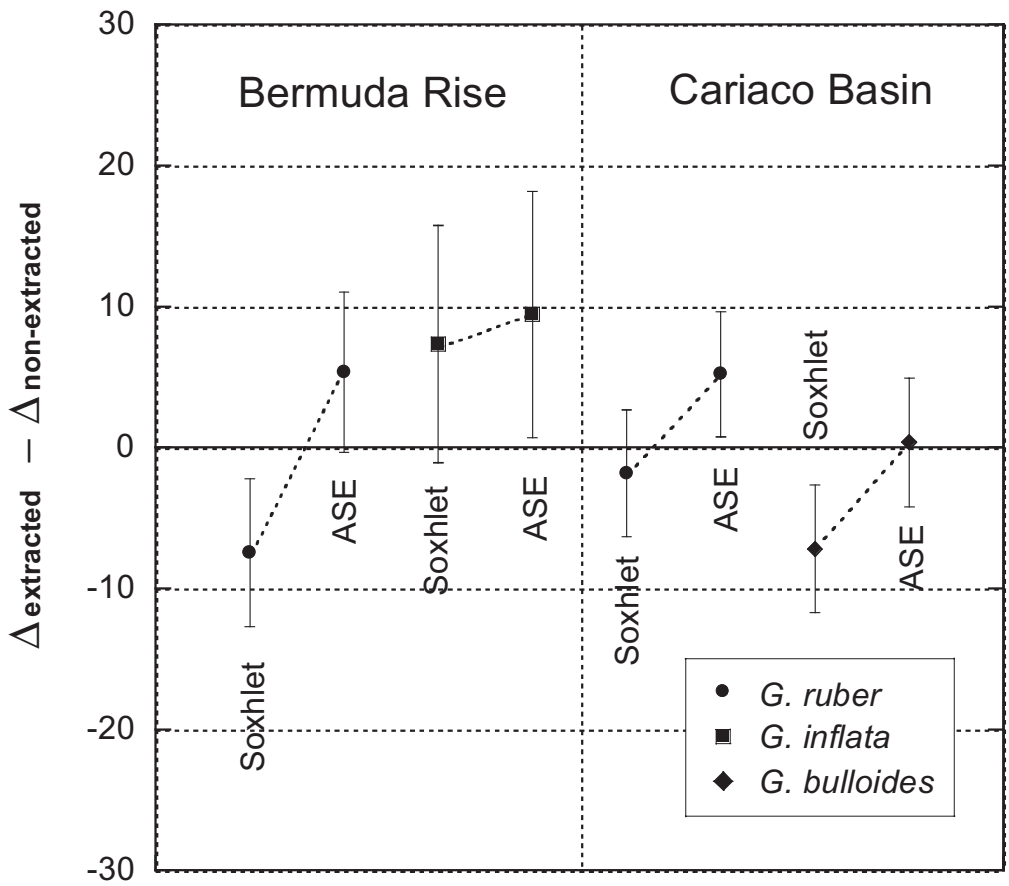

Figure 3 Foraminiferal $\Delta^{14} \mathrm{C}$ difference between the solvent-extracted and non-extracted samples from Bermuda Rise and Cariaco Basin sediments. Broken lines indicate pairs of Soxhlet- and ASE-extracted samples.

\section{ACKNOWLEDGMENTS}

Eben Franks and the crew of the R/V Oceanus are thanked for assistance in obtaining the Bermuda Rise core. We also thank Eben Franks, Daniel Montluçon, and Sean Sylva for laboratory assistance, NOSAMS staff for analytical support, and Timothy Jull for comments on the manuscript. This work was financially supported by NSF grant 9809624 . N Ohkouchi was supported by a fellowship from Japan Society for the Promotion of Science.

\section{REFERENCES}

Bowman S. 1990. Radiocarbon Dating: Interpreting the Past. Berkeley: University California Press. 64 p.

Bradley RS. 1999. Paleoclimatology: Reconstructing Climates of the Quaternary. 2nd ed. San Diego: Academic Press. 613 p.

Brassell SC. 1993. Applications of biomarkers for delineating marine paleoclimatic fluctuations during the Pleistocene. In: Engel MH, Macko SA, editors. Organic Geochemistry. New York: Plenum Press. p 699-738.

Broecker WS, Peng TH. 1980. Seasonal variability in the ${ }^{14} \mathrm{C} /{ }^{12} \mathrm{C}$ ratio for surface ocean water. Geophysical Research Letters 7:1020-2.

Deuser WG, Ross EH. 1989. Seasonally abundant planktonic foraminifera of the Sargasso Sea: succession, deep-water fluxes, isotopic compositions, and paleoceanographic implications. Journal of Foraminifera
Research 19:268-93

Harris PG, Zhao M, Rosell-Melé A, Tiedemann R, Sarnthein M, Maxwell JR. 1996. Chlorin accumulation rate as a proxy for Quaternary marine primary productivity. Nature 383:63-5.

Herbert TD, Schuffert JD, Thomas D, Lange C, Weinheimer A, Peleo-Alampay A, Herguera J-C. 1998. Depth and seasonality of alkenone production along the California margin inferred from a core top transect. Paleoceanography 13:263-71.

Hughen KA, Overpeck JT, Peterson LC, Trumbore S. 1996. Rapid climate changes in the tropical Atlantic region during the last deglaciation. Nature 380:51-4.

Hughen KA, Eglinton TI, Xu L, Maku M. 2004. Abrupt tropical vegetation response to rapid climate changes. Science 304:1955-9.

Keigwin LD, Boyle EA. 2000. Detecting Holocene 
changes in thermohaline circulation. Proceedings National Academy of Sciences 97:1343-6.

Levin I, Kromer B, Schoch-Fischer H, Bruns M, Münnich M, Berdau D, Vogel JC, Münnich KO. 1985. 25 years of tropospheric ${ }^{14} \mathrm{C}$ observations in Central Europe. Radiocarbon 27(1):1-19.

Lin HL, Peterson LC, Overpeck JT, Trumbore SE, Murray DW. 1997. Late Quaternary climate change from $\delta^{18} \mathrm{O}$ records of multiple species of planktonic foraminifera: high-resolution records from the anoxic Cariaco Basin, Venezuela. Paleoceanography 12:415-27.

McNichol AP, Osborne EA, Gagnon AR, Fry B, Jones GA. 1994. TIC, TOC, DIC, DOC, PIC, POC - unique aspects in the preparation of oceanographic samples for ${ }^{14} \mathrm{C}$-AMS. Nuclear Instrument and Methods in Physics Research B 92:162-5.

Meyers PA. 1997. Organic geochemical proxies of paleoceanographic, paleolimnologic, and paleoclimatic processes. Organic Geochemistry 27:213-50.

Mollenhauer G, Eglinton TI, Ohkouchi N, Schneider RR, Muller PJ, Grootes PM, Rullkotter J. 2003. Asynchronous alkenone and foraminifera records from the Benguela Upwelling System. Geochimica et Cosmochimica Acta 67:2157-71.

Mollenhauer G, Kienast M, Lamy F, Meggers H, Schneider RR, Hayes JM, Eglinton TI. 2005. An evaluation of ${ }^{14} \mathrm{C}$ age relationships between co-occurring foraminifera, alkenones, and total organic carbon in continental margin sediments. Paleoceanography 20: PA1016, doi:10.1029/2004PA001103.

Mollenhauer G, Montluçon D, Eglinton TI. 2005. Radiocarbon dating of alkenones from marine sediments: II. Assessment of carbon process blanks. Radiocarbon, this issue, $\mathrm{p}$ 413-24.

Ohkouchi N, Kawamura K, Taira A. 1997. Molecular pa- leoclimatology: reconstruction of climate variabilities in the late Quaternary. Organic Geochemistry 27:17383.

Ohkouchi N, Eglinton TI, Keigwin LD, Hayes JM. 2002. Spatial and temporal offsets between proxy records in a sediment drift. Science 298:1224-7.

Ohkouchi N, Xu L, Reddy CM, Montluçon D, Eglinton TI. 2005. Radiocarbon dating of alkenones from marine sediments: I. Isolation protocol. Radiocarbon, this issue, $\mathrm{p} 401-12$.

Pagani M, Freeman KH, Ohkouchi N, Caldeira K. 2002. Comparison of water column $\left[\mathrm{CO}_{2 \mathrm{aq}}\right]$ with sedimentary alkenone-based estimates: a test of the alkenone$\mathrm{CO}_{2}$ proxy. Paleoceanography 17:2002PA000756.

Pearson A, McNichol AP, Schneider RJ, von Reden KF. 1998. Microscale AMS ${ }^{14} \mathrm{C}$ measurement at NOSAMS. Radiocarbon 40(1):61-75.

Richter BE. 1999. The extraction of analytes from solid samples using accelerated solvent extraction. $L C$ - $G C$ 17:S22-S28.

Rostek F, Ruhland G, Bassinot FC, Müller PJ, Labeyrie LD, Lancelot Y, Bard E. 1993. Reconstructing sea surface temperature and salinity using $\delta^{18} \mathrm{O}$ and alkenone records. Nature 364:319-21.

Sachs JP, Lehman SJ. 1999. Subtropical North Atlantic temperatures 60,000 to 30,000 years ago. Science 286: 756-9.

Schleicher M, Grootes PM, Nadeau M-J, Schoon A. 1998. The carbonate ${ }^{14} \mathrm{C}$ background and its components at the Leibniz AMS facility. Radiocarbon 40(1): 85-93.

Sinninghe Damsté JS, Köster J. 1998. A euxinic southern North Atlantic Ocean during the Cenomanian/Turonian oceanic anoxic event. Earth and Planetary Science Letters 158:165-73. 